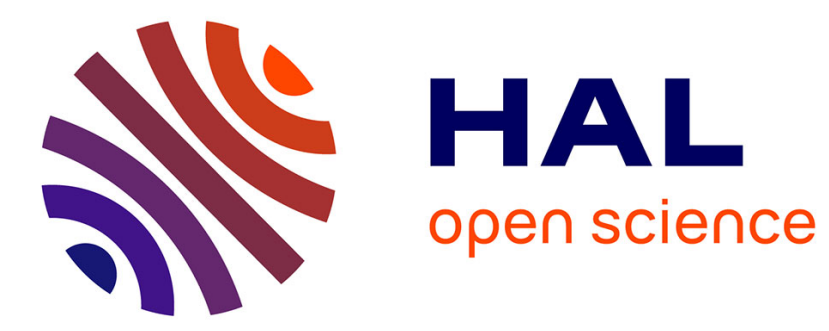

\title{
The monopolist is not the best environmentalist's best friend: An example
}

Philippe Mahenc, Marion Podesta

\section{To cite this version:}

Philippe Mahenc, Marion Podesta. The monopolist is not the best environmentalist's best friend: An example. Economics Letters, 2012, 115 (3), pp.379-382. hal-00955470

\section{HAL Id: hal-00955470 \\ https://hal.science/hal-00955470}

Submitted on 4 Mar 2014

HAL is a multi-disciplinary open access archive for the deposit and dissemination of scientific research documents, whether they are published or not. The documents may come from teaching and research institutions in France or abroad, or from public or private research centers.
L'archive ouverte pluridisciplinaire HAL, est destinée au dépôt et à la diffusion de documents scientifiques de niveau recherche, publiés ou non, émanant des établissements d'enseignement et de recherche français ou étrangers, des laboratoires publics ou privés. 


\title{
The monopolist is not the best environmentalist's best friend: An example
}

\author{
Philippe MAHENC* $\quad$ Marion PODESTA ${ }^{\dagger}$
}

December 12, 2011

\begin{abstract}
This letter addresses the second-degree price discrimination issue when a monopolized product is tied with environmental quality. The monopolist may degrade environmental quality too much when marginal valuations of environmental quality and the good itself are positively related across consumers.

Keywords: environmental quality; public good; price discrimination; tying

JEL classification: D42; L12; Q5
\end{abstract}

\section{Introduction}

The famous discussion of railroad tariffs for passenger traffic in Dupuit (1849) suggests that a monopolist finds it advantageous both to degrade the quality intended for the poor and enhance that intended for the rich in order to discriminate prices.

What the company is trying to do is prevent the passengers who can pay the second-class fare from traveling third-class; it hits the poor, not because it wants to hurt them, but to frighten the rich... And it is again for the same reason that the companies, having proved almost cruel to the third-class passengers and mean to the second-class ones, become lavish in dealing with first-class passengers. Having refused the poor what is necessary, they give the rich what is superfluous. ${ }^{1}$

Most of the formal models stemming from Mussa and Rosen (1978) have emphasized that imperfect discrimination leads to a degradation in the quality of the product offered to the consumers with a low willingness-to-pay. This makes the product less attractive to consumers with a high willingness-to-pay, which allows the monopolist to segment the market. One exception is Srinagesh and Bradburd (1989) who demonstrate the idea that quality discrimination can also lead to providing too much quality to the consumers with a high willingness-to-pay. The common intuition underlying these results is that asymmetric information creates a negative externality for the monopolist. Internalizing

${ }^{*}$ LAMETA, Montpellier I University, Avenue Raymond Dugrand, Site de Richter, C. S. 79606, 34960 Montpellier Cedex 2 - France - and Toulouse School of Economics. Financial support from the French Agence Nationale de la Recherche is gratefully acknowledged.

†E-mail: marion.podesta@univ-savoie.fr ; Tel: +33 (0)4 500924 46, IREGE, University of Savoie, 4 Chemin de Bellevue, BP 80439 Annecy-le-Vieux, France.

${ }^{1}$ Dupuit (1849), as quoted in Ekelund (1970). 
this externality requires preventing consumers of one type from switching to the quality intended for another type.

In this literature, quality is treated as an excludable characteristic of the good, that is, the user of the good tied ${ }^{2}$ with one level of quality can be excluded from consuming the good tied with another level of quality. If however quality is environmental, than no one can be prevented from enjoying the level of environmental quality offered to the users of the good, whatever the quantity purchased. Our purpose is to examine the provision of environmental quality by a discriminating monopolist in a model that treats environmental quality not only as a vertical attribute ${ }^{3}$ of the monopolized good, but also as a non-excludable characteristic.

In our model, consumer preferences are such that there is a positive correlation between the valuation of the tying good and the tied environmental quality, as illustrated for instance by a ski resort. Indeed, we expect a consumer with a high willingness-to-pay for the ski resort to be more environmentally friendly too. In this note, we show that the monopolist may provide an inefficiently low level of environmental quality given the price-quantity combinations offered to consumers. This result departs from the view popularized by Buchanan (1969) that a polluting monopolist behaves in a more efficient way than does a polluting competitive firm because the output reduction due to the exercise of monopoly power scales down the harm done to the environment (see also Barnett (1980), for more on this point).

\section{The model}

The monopolist supplies a good or a service tied with an environmental service to the consumer. This service provides environmental quality at some level measured by the index $e$. Environmental quality will be treated as a public good that is not excludable. The level of environmental quality is set by the monopolist, i.e., $e$ is a choice variable. If, for instance, the monopolist provides recreational activities by a lake, he will also control the quality of water and the cleanliness of the banks. Similarly, the choice of environmental quality in a ski resort may be determined by a number of variables including the fuelefficiency of ski lifts, the ski resort location and its blending into the natural surroundings.

The monopolist faces a demand composed of two types of consumers differentiated by their taste for the good. There is no exogenous signal of each consumer type $i=1,2$. The proportion of consumer type $i$ in the market place is $\lambda_{i}$.

Assume a quasi-linear utility function for consumers of type $i$

$$
u_{i}=b_{i}\left(q_{i}, e\right)+x_{i}
$$

where $x_{i}$ is consumption of the numeraire commodity, $q_{i}$ is the consumption of the good tied with environmental quality $e$, and $b_{i}(0, e)=0$. Our specification of preferences follows Carbone and Smith (2007) in that the environmental externality is not separable from private consumption. This captures an environmental feedback on demand: changes in environmental quality do influence the consumption behavior.

\footnotetext{
${ }^{2}$ Tying is the practice requiring the consumer of one good (or service) to also purchase a second good (or service).

${ }^{3}$ This assumption follows the recent approach in the environmental literature. It can be found for instance in Arora and Gangopadhyay (1995), Bansal and Gangopadhyay (2003), Amacher et al. (2004) and André et al. (2009).
} 
We normalize the price of numeraire to equal 1 , and we let $t_{i}$ denote total spending on the quantity of good purchased by consumer $i$ from the monopolist.

Consumer $i$ 's budget constraint is

$$
t_{i}+x_{i}=r_{i}
$$

where $r_{i}$ is the consumer's initial endowment of the numeraire. We can write net utility as

$$
u_{i}=b_{i}\left(q_{i}, e\right)-t_{i}+r_{i}
$$

Partial derivatives $\partial b_{i} / \partial q_{i}=P_{i}\left(q_{i}, e\right)$ and $\partial b_{i} / \partial e$ represent, respectively, consumer $i$ 's marginal willingness-to-pay (MWTP) for the good and his MWTP for environmental quality.

Assumptions 1: For all $(q, e), b_{1}(q, e)<b_{2}(q, e)$ and $\partial b_{1} / \partial q=P_{1}(q, e)<\partial b_{2} / \partial q=$ $P_{2}(q, e)$.

High-demand consumers 2 are willing to pay more than low-demand consumers 1 for both a given amount of the good and environmental quality. Moreover, high-demand consumers' MWTP exceeds that of low-demand consumers.

We will specialize the model so that $b_{i}(q, e)=e q\left(\theta_{i}-q / 2\right)$, where $\theta_{i}$ represents the taste for the good, with $\theta_{1}<\theta_{2}$. This specification extends Mussa and Rosen (1978) to preferences defined over a public good. MWTPs are $P_{i}(q, e)=e\left(\theta_{i}-q\right)$ for the good and $\partial b_{i} / \partial e=q\left(\theta_{i}-q / 2\right)$ for environmental quality. Note that, for all $q$ such that $P_{i}(q, e)>0$, we have $\partial b_{i} / \partial e>0$, that is, both types of consumers $\theta_{1}$ and $\theta_{2}$ prefer the good to be more environmentally friendly. This follows the recent approach in environmental literature that considers environmental quality as a vertical attribute of the good. In addition, $\partial b_{1} / \partial e<\partial b_{2} / \partial e$ means that the high-demand consumers are more concerned about environmental quality than the low-demand consumers. This fits in with outdoor leisure activities such as skiing, sailing, walking or fishing since the more people are fond of such activities, the more they feel concerned about the environment.

Let the cost of producing one unit of the good tied with environmental quality $e$ be $c(e)$, where $c(e)$ is an increasing and convex function of $e$. This implies that a cleaner good is more costly to produce: the resources allocated by the monopolist to pollution abatement and wastes cleanup raise the production costs. To make things interesting, we will assume that supplying the good to any type of consumer on the market is socially efficient, that is,

Assumption 2: $\theta_{1}-\frac{c(e)}{e}>0$.

\section{Social optimum}

Given that the total amount of the numeraire available for distribution among consumers is $\sum_{i=1}^{2} \lambda_{i} r_{i}-c(e) \sum_{i=1}^{2} \lambda_{i} q_{i}$, the optimization problem of the benevolent planner is

$$
\max _{q_{1}, q_{2}, e} W\left(q_{1}, q_{2}, e\right) \equiv \sum_{i=1}^{2} \lambda_{i} b_{i}\left(q_{i}, e\right)+\sum_{i=1}^{2} \lambda_{i} r_{i}-c(e) \sum_{i=1}^{2} \lambda_{i} q_{i}
$$


Assuming an interior solution $\left(q_{1}^{*}, q_{2}^{*}, e^{*}\right)$, conditions for a social optimum are

$$
\begin{aligned}
P_{i}\left(q_{i}^{*}, e^{*}\right) & =c\left(e^{*}\right), i=1,2 \\
\sum_{i=1}^{2} \lambda_{i} \partial b_{i} / \partial e & =c^{\prime}\left(e^{*}\right) \sum_{i=1}^{2} \lambda_{i} q_{i}^{*}
\end{aligned}
$$

From (4), social efficiency requires that the low- and high-demand consumers have the same MWTP for the good, equal to the marginal cost of producing the good. Moreover, by condition (5), the weighted sum of MWTPs for environmental quality equals the marginal cost of providing this quality.

\section{First-degree price discrimination}

Suppose first that the monopolist perfectly observes the type of each consumer. The monopolist wants to offer consumers $i=1,2$ some price, quantity and environmental quality combination $\left(t_{i}, q_{i}, e\right)$ that yields the maximum profit. This combination is a take it or leave it offer: consumer $i$ can either pay $t_{i}$, consume $q_{i}$ and enjoy environmental quality $e$, or buy and pay nothing.

The profit maximization problem of the monopolist is

$$
\max _{t_{1}, t_{2}, q_{1}, q_{2}, e} \sum_{i=1}^{2} \lambda_{i}\left(t_{i}-c(e) q_{i}\right)
$$

such that $b_{i}\left(q_{i}, e\right)-t_{i} \geq 0, i=1,2(I R)$.

Individual rationality constraints $(I R)$ require that each type of consumer be willing to purchase. Equality will hold for each one since the monopolist wants $t_{i}$ to be as large as possible.

$$
b_{i}\left(q_{i}, e\right)-t_{i}=0, i=1,2
$$

Substituting from the constraints, we get exactly the same optimization problem as that faced by the benevolent planner. Note that the monopolist behaves in a socially desirable way here because all consumer surplus goes to the monopolist.

\section{Second-degree price discrimination}

Suppose now that the monopolist cannot tell the consumers apart. Due to asymmetric information, consumers may have the temptation to choose the "wrong" combination of price, quantity, and environmental quality, i.e., the one not intended for their type. In addition to previous individual rationality constraints, two further incentive compatibility constraints, $\left(I C_{i}\right), i=1,2$, now bind the monopolist. The problem facing the monopolist is

$$
\begin{gathered}
\max _{t_{1}, t_{2}, q_{1}, q_{2}, e} \sum_{i=1}^{2} \lambda_{i}\left(t_{i}-c(e) q_{i}\right) \\
\text { s.t. }\left\{\begin{array}{c}
b_{1}\left(q_{1}, e\right)-t_{1} \geq b_{1}\left(q_{2}, e\right)-t_{2}\left(I C_{1}\right) \\
b_{2}\left(q_{2}, e\right)-t_{2} \geq b_{2}\left(q_{1}, e\right)-t_{1}\left(I C_{2}\right) \\
b_{1}\left(q_{1}, e\right)-t_{1} \geq 0\left(I R_{1}\right) \\
b_{2}\left(q_{2}, e\right)-t_{2} \geq 0\left(I R_{2}\right)
\end{array}\right.
\end{gathered}
$$


As a preliminary result, we demonstrate that the output quantities now supplied to both types of consumers verify $q_{1}^{m} \leq q_{2}^{m}$.

Adding $\left(I C_{1}\right)$ to $\left(I C_{2}\right)$ yields

$$
b_{1}\left(q_{1}, e\right)-b_{2}\left(q_{1}, e\right) \geq b_{1}\left(q_{2}, e\right)-b_{2}\left(q_{2}, e\right) .
$$

From Assumptions 1, we have $\partial b_{1} / \partial q-\partial b_{2} / \partial q<0$. Thus, inequality (8) implies $q_{1}^{m} \leq q_{2}^{m}$.

Let us now show that inequalities $\left(I C_{2}\right)$ and $\left(I R_{1}\right)$ are binding constraints in the solution of the monopolist's problem.

As usual, the proof is by contradiction. Indeed, suppose it is not so. Then the monopoly could either raise $t_{2}$ or (and) $t_{1}$ by a small amount so that market segmentation remains unchanged, i.e., the high-demand consumer is still worse off switching to the combination $\left(t_{1}, q_{1}, e\right)$ intended for the low-demand consumer, and the latter still accepts $\left(t_{1}, q_{1}, e\right)$. This would increase the monopolist's profit, thereby leading to a contradiction: such an increase cannot happen in a profit-maximizing solution.

Hence, the binding constraints $\left(I R_{1}\right)$ and $\left(I C_{2}\right)$ yield

$$
\begin{aligned}
b_{1}\left(q_{1}, e\right) & =t_{1} \text { and } \\
t_{1}-t_{2} & =b_{2}\left(q_{1}, e\right)-b_{2}\left(q_{2}, e\right) .
\end{aligned}
$$

In the solution of the profit-maximizing problem, the monopoly extracts the whole surplus of the low-demand consumer, as shown by (9). Moreover, equality (10) says that highdemand consumers are charged the highest price that just induces their consumption of the quantity directed at them.

Turning now to constraints $\left(I R_{2}\right)$ and $\left(I C_{1}\right)$, we show that they can be eliminated as being nonbinding.

First, $\left(I R_{1}\right)$ and $\left(I C_{2}\right)$ immediately imply $\left(I R_{2}\right)$ since $b_{1}\left(q_{1}, e\right)<b_{2}\left(q_{1}, e\right)$. Hence, the high-demand consumer obtains here an extra surplus $u_{2}-r_{2}>0$ compared to the first-best solution.

Second, using (10), the constraint $\left(I C_{1}\right)$ can be rewritten

$$
b_{1}\left(q_{1}, e\right)-b_{1}\left(q_{2}, e\right) \geq b_{2}\left(q_{1}, e\right)-b_{2}\left(q_{2}, e\right)=t_{1}-t_{2} .
$$

From Cauchy's generalized mean value theorem, there exists at least one $q$ with $q_{1}<q<$ $q_{2}$ such that

$$
\frac{b_{1}\left(q_{1}, e\right)-b_{1}\left(q_{2}, e\right)}{\partial b_{1}(q) / \partial q}=\frac{b_{2}\left(q_{1}, e\right)-b_{2}\left(q_{2}, e\right)}{\partial b_{2}(q) / \partial q} .
$$

We know from Assumptions 1 that $\partial b_{1} / \partial q<\partial b_{2} / \partial q$. As moreover $q_{1} \leq q_{2}$, we have $b_{2}\left(q_{1}, e\right)-b_{2}\left(q_{2}, e\right) \leq 0$, and so

$$
\left[b_{2}\left(q_{1}, e\right)-b_{2}\left(q_{2}, e\right)\right] \frac{\partial b_{1}(q) / \partial q}{\partial b_{2}(q) / \partial q}>b_{2}\left(q_{1}, e\right)-b_{2}\left(q_{2}, e\right) .
$$

Using (10), this inequality can be rewritten

$$
\left[b_{2}\left(q_{1}, e\right)-b_{2}\left(q_{2}, e\right)\right] \frac{P_{1}(q, e)}{P_{2}(q, e)}>t_{1}-t_{2} .
$$

Furthermore (12) implies

$$
b_{1}\left(q_{1}, e\right)-b_{1}\left(q_{2}, e\right)=\left[b_{2}\left(q_{1}, e\right)-b_{2}\left(q_{2}, e\right)\right] \frac{P_{1}(q, e)}{P_{2}(q, e)} .
$$


We finally conclude from (14) that

$$
b_{1}\left(q_{1}, e\right)-b_{1}\left(q_{2}, e\right)>t_{1}-t_{2} .
$$

Therefore, inequality $\left(I C_{1}\right)$ will be a nonbinding constraint.

This simplification in the number of relevant constraints leaves us with both binding constraints $\left(I C_{2}\right)$ and $\left(I R_{1}\right)$. Substituting (9) and (10) into (7), we obtain a reduced program $\max _{q_{1}, q_{2}, e} \Pi\left(q_{1}, q_{2}, e\right)$. Assuming an interior solution $\left(q_{1}^{m}, q_{2}^{m}, e^{m}\right)$, the first-order conditions based on the effective constraints are

$$
\begin{gathered}
P_{2}\left(q_{2}^{m}, e^{m}\right)=c\left(e^{m}\right) \\
P_{1}\left(q_{1}^{m}, e^{m}\right)+\frac{\lambda_{2}}{\lambda_{1}}\left(P_{1}\left(q_{1}^{m}, e^{m}\right)-P_{2}\left(q_{1}^{m}, e^{m}\right)\right)=c\left(e^{m}\right) \\
\lambda_{1} \partial b_{1}\left(q_{1}^{m}, e^{m}\right) / \partial e+\lambda_{2} \partial b_{2}\left(q_{2}^{m}, e^{m}\right) / \partial e-\lambda_{2}\left(\partial b_{2}\left(q_{1}^{m}, e^{m}\right) / \partial e-\partial b_{1}\left(q_{1}^{m}, e^{m}\right) / \partial e\right) \\
=c^{\prime}\left(e^{m}\right)\left(\lambda_{2} q_{2}^{m}+\lambda_{1} q_{1}^{m}\right) .
\end{gathered}
$$

Conditions (17) and (18) yield the familiar result of monopolistic imperfect quantity discrimination: the high-demand consumer purchases the socially optimal amount of the good, while the low-demand consumer purchases an inefficiently small amount of the good. In the words of Dupuit (1849), the monopolist "hits the poor" with a reduction in quantity because the low-demand consumer suffers relatively less from reduced quantity than the high-demand consumer. This makes the combination $\left(t_{1}^{m}, q_{1}^{m}, e^{m}\right)$ less attractive to the high-demand consumer.

Using the specification $b_{i}(q, e)=e q\left(\theta_{i}-q / 2\right)$, we obtain from (18)

$$
q_{1}^{m}=\theta_{1}-\frac{\lambda_{2}}{\lambda_{1}}\left(\theta_{2}-\theta_{1}\right)-\frac{c\left(e^{m}\right)}{e^{m}} .
$$

Observe that $\lambda_{2}$ must be sufficiently low to get the existence of an interior solution for $q_{1}^{m}$. More precisely, $q_{1}^{m}>0$ only if $\lambda_{2}<\bar{\lambda} \equiv \frac{\theta_{1}-c\left(e^{m}\right) / e^{m}}{\theta_{2}-c\left(e^{m}\right) / e^{m}}$. When the proportion of high-demand consumers is above $\bar{\lambda}$, the monopolist is worse off attracting low-demand consumers to the market. Given $q_{1}^{m}=0$, the monopolist provides the socially efficient level of environmental quality to high-demand consumers since condition (19) can be rewritten

$$
\frac{\partial \Pi\left(q_{1}^{m}, q_{2}^{m}, e^{m}\right)}{\partial e}=\frac{\partial W\left(q_{1}^{m}, q_{2}^{m}, e^{m}\right)}{\partial e}=0 .
$$

Suppose now $\lambda_{2}<\bar{\lambda}$, so that low-demand consumers are not excluded from the market. From (4), we know that $q_{1}^{*}=\theta_{1}-\frac{c\left(e^{m}\right)}{e^{m}}$. From (20), second-degree price discrimination involves a $\frac{\lambda_{2}}{\lambda_{1}}\left(\theta_{2}-\theta_{1}\right)$ reduction in the quantity intended for low-demand consumers.

If we specialize the model as previously mentioned, we have $\partial b_{2}\left(q_{1}, e\right) / \partial e-\partial b_{1}\left(q_{1}, e\right) / \partial e=$ $q_{1}\left(\theta_{2}-\theta_{1}\right)>0$. Substituting this into (19), we have

$$
\frac{\partial \Pi\left(q_{1}^{m}, q_{2}^{m}, e^{m}\right)}{\partial e}=\frac{\partial W\left(q_{1}^{m}, q_{2}^{m}, e^{m}\right)}{\partial e}-\lambda_{2} q_{1}^{m}\left(\theta_{2}-\theta_{1}\right)=0 .
$$

Thus, $q_{1}^{m}>0$ implies $\frac{\partial W\left(q_{1}^{m}, q_{2}^{m}, e^{m}\right)}{\partial e}>0$, and so, given $\left(q_{1}^{m}, q_{2}^{m}\right)$, the monopolist provides an inefficiently low level of environmental quality. The intuition is that consumer's 
private information induces the high-demand consumer to switch to the monopolist's offer of the combination designed for the low-demand consumer. This masquerade reduces the high-demand consumer's valuation of environmental quality from $\partial b_{2}\left(q_{2}, e\right) / \partial e$ to $\partial b_{2}\left(q_{2}, e\right) / \partial e-\left(\partial b_{2}\left(q_{1}, e\right) / \partial e-\partial b_{1}\left(q_{1}, e\right) / \partial e\right)$. As can be seen in the left-hand side of (19), the monopolist internalizes the inclination of high-demand consumers to pay less for environmental quality than they are actually willing to pay. This yields level of environmental quality which is too low.

Proposition 1. If $q_{1}^{m}<q_{1}^{*}$ and $q_{2}^{m}=q_{2}^{*}$, then

- if $\bar{\lambda} \leq \lambda_{2}$, the monopolist removes the low-demand consumers from the market and provides the socially efficient level of environmental quality;

- if $0<\lambda_{2}<\bar{\lambda}$, the monopolist serves both types of consumers and underprovides environmental quality.

Following the evocative expression of Dupuit (1849), the monopolist "hits the poor" twice when their group is so large that $\lambda_{2}<\bar{\lambda}$. First, the monopolist reduces the output quantity in the combination proposed to low-demand consumers, in order to make it unattractive to high-demand consumers. Second, the monopolist offers an inefficiently low level of environmental quality, thereby "hitting the rich" too. The reason is that the monopolist underestimates the high-demand consumers' valuation of environmental quality by internalizing their tendency to masquerade as low-demand consumers. This result may explain why the environment is not sufficiently protected in very popular sites supplying recreational activities. If, for instance, the environmental indicator is how the buildings and infrastructure of a ski resort melt into the background, laxity on this point is more likely to be observed in places crowded with low-demand consumers. When the group of high-demand consumers is so large that $\bar{\lambda} \leq \lambda_{2}$, the monopolist deters lowdemand consumers from purchasing the good and sets the efficient level of environmental quality.

\section{References}

[1] Amacher, G. S., Koskela, E., Ollikainen, M., 2004. Environmental quality competition and eco-labeling. Journal of Environmental Economics and Management 47, $284-306$.

[2] André, F. J., Gonzalez, P., Porteiro, N., 2009. Strategic quality competition and the Porter Hypothesis. Journal of Environmental Economics and Management 57, $182-194$.

[3] Arora, S., Gangopadhyay, S., 1995. Toward a theoretical model of voluntary overcompliance. Journal of Economic Behaviour and Organisation 28, 289-309.

[4] Bansal, S., Gangopadhyay, S., 2003. Tax/subsidy policies in the presence of environmentally aware consumers. Journal of Environmental Economics and Management $45,333-355$.

[5] Barnett, A. H., 1980. The Pigouvian tax rule under monopoly. American Economic Review 70, 1037-1041. 
[6] Buchanan, J. M., 1969. External diseconomies, corrective taxes and market structure. American Economic Review 59, 174-177.

[7] Carbone, J. C., Smith, V. K., 2007. Evaluating policy interventions with general equilibrium externalities. Journal of Public Economics 92, 1254-1274.

[8] Dupuit, J., 1849. On tolls and transport charges. Annales des ponts et chaussées.

[9] Ekelund, R. B. JR., 1970. Price discrimination and product differentiation in economic theory: An early analysis. Quarterly Journal of Economics 84, 268-278.

[10] Mussa, M., Rosen, S., 1978. Monopoly and product quality. Journal of Economic Theory 18, 301-317.

[11] Palmer, K., Oates, W. E., Portney P. R., 1995. Tightening environmental standards: The benefit cost or the no-cost paradigm? Journal of Economic Perspectives 9, 119 132.

[12] Srinagesh, P., Bradburd, R. M., 1989. Quality distortion by a discriminating monopolist. American Economic Review 79, 96-105. 